\title{
The frequency, implications, and strategies for the reduction of COPD readmissions
}

\author{
Kavitha Selvan BS, Hawa Edriss MD, Austin Castillo BS
}

\section{Chronic obstructive pulmonary disease} (COPD) is a significant burden to the health care system in the United States and accounts for a large portion of its expenditures. It is the fourth leading cause of death in the United States and is associated with decreased quality of life. Patients hospitalized for acute exacerbations of COPD (AECOPD) have a $65 \%$ increased risk for readmissions in the following year. ${ }^{1}$ Ford reports that approximately 13.7 million adults $(6.5 \%)$ had the diagnosis of COPD in $2011 .{ }^{2}$ In 2010, there were approximately 699,000 hospitalizations for COPD in adults > 25 years old. The number of acute exacerbations ranges from 0.5 to 3.5 exacerbations per patient per year. ${ }^{3}$ The average length of stay for a patient admitted to the hospital for an acute exacerbation in 2012 was 4 days. The cost for an admission has steadily increased and was reported at $\$ 7,706$ per patient in 2012. Overall, 500,000 patients with AECOPD are hospitalized in the United States with a total cost of $\$ 18$ billion annually. ${ }^{4}$ Approximately $14 \%$ of patients with COPD will be readmitted within the first month after discharge and an additional $7 \%$ will be readmitted within three months. ${ }^{5}$

Readmissions for AECOPD have significant implications for patients. Guerrero found that patients who were readmitted within 30 days of discharge for AECOPD had an absolute increase in mortality of $4 \%$ within the next 30 days compared to patients who were not readmitted, and that the risk increases to $24 \%$ over the next three years. ${ }^{6}$ Readmissions for AECOPD occur in clusters rather than at random. ${ }^{7}$ This cluster analysis indicates that the highest risk for readmission occurs within eight weeks following the initial exacerbation. These readmissions may reflect more severe disease as an explanation for readmission or might occur early because the patient has not satisfactorily recovered from the initial hospitalization.
Multiple factors influence readmission rates in patients with COPD. These include disease severity, comorbid conditions, access to medical care, and compliance with medical care. Tsui and coworkers followed 255 patients who had been admitted with AECOPD for one year and found that 183 patients $(73.2 \%)$ were readmitted at least once with a new exacerbation. ${ }^{8}$ The need for non-invasive ventilation for an acute exacerbation, a higher COPD Assessment Test score, a shorter 6-minute walk distance, and the number of admissions during the previous year were all independently associated with readmissions. The subgroup with very frequent readmissions ( $\geq 4$ per year) had significant anxiety based on the Hospital Anxiety and Depression Score. Almagro prospectively evaluated 129 patients hospitalized with AECOPD. ${ }^{9}$ During the one year follow-up period, more than $50 \%$ of these patients were readmitted. Based on multivariable analysis, the best predictors of readmission were the combination of hospitalization for COPD in the previous year, a total Saint George's Respiratory Questionnaire score $\geq 50$ points, and a discharge $\mathrm{PaCO} 2 \geq 45 \mathrm{mmHg}$. These two studies indicate that severe disease based on symptoms, or an abnormal functional status, or an elevated $\mathrm{PaCO} 2$ and frequent admissions identify patients at risk for readmission within the next one year.

Health insurance organizations, including the Centers for Medicare \& Medicaid Services, have directed hospitals to reduce AECOPD readmissions by reducing reimbursement and applying penalties to hospitals with increased AECOPD readmission rates. An important strategy to reduce the COPD readmission is to identify risk factors that result in hospitalization and intervene before discharge. This approach can improve survival and quality of life. ${ }^{10}$ Prior studies indicate that multidisciplinary discharge and other resource intensive plans are sometimes effective in readmission rate reduction. 
However, additional resources are usually needed for these efforts. For instance, Koehler and his colleague used a discharge care bundle with an integrated education program with 41 patients and found a reduction in 30-day readmission or emergency center visit rates. This study,however, included only four patients with COPD. ${ }^{11} \mathrm{~A}$ different result was seen in a more recent randomized trial in which 172 patients were randomized to a standard care group or discharge bundle group. The care bundle group received smoking cessation counseling, inhaler technique education, screening for gastro-esophageal reflux disease, depression, and anxiety, and a 48 hour post-discharge call. This study showed no difference between the two groups in the risk of hospitalization or emergency center visits for AECOPD during the 30 days after discharge. ${ }^{12}$ The educational program in the Koehler study was extended up to a week following discharge, which may account for part of the differences between these two studies.

Another strategy used to prevent readmission for AECOPD is prompt follow-up after discharge from the hospital. Gavish et al retrospectively reviewed 195 patients with AECOPD over a six year period and studied the impact of early follow-up visits on readmission rates. Follow-up visits with a pulmonologist occurred within 30 days of discharge in $44 \%$ of patients. The primary outcome, relative risk for recurrence of AECOPD within 90 days of the previous AECOPD, was significantly higher in patients who did not have a follow-up visit within 30 days of discharge (RR 2.91, 95\% Cl 1.06-8.01). ${ }^{13}$ The National COPD Readmissions Summit in October 2013 provided guidelines and recommendations to reduce the 30-day COPD readmission, though some of these measures lacked evidence-based support. These measures include the use of COPD treatment protocols for emergency center and hospitalized patients, action plans for AECOPD, optimal inhaler technique, patient education on smoking cessation, patient assessment for oxygen, comorbidities management, a follow-up plan that includes a provider visit within seven days, a post-discharge phone call at 48-72 hours following discharge, and pulmonary rehabilitation when available. ${ }^{14}$ Many COPD readmissions are caused other than AECOPD. These include pneumonia, congestive heart failure, acute myocardial infarction, arrhythmia, and acute pulmonary edema and need careful management. Postdischarge interventions, such as pulmonary rehabilitation, have been shown to reduce AECOPD rate. ${ }^{15}$

Key words- editorial, patient readmission, chronic obstructive pulmonary disease

Author Affiliation: Hawa Edriss is a fellow in Pulmonary and Critical Care Medicine at Texas Tech University Health Sciences Center in Lubbock, TX.

Submitted: 06/16/2016

Published electronically: 07/15/2016

Conflict of Interest Disclosures: none

Corresponding Author: Hawa Edriss MD

Contact Information: hawa.edriss@ttuhsc.edu

DOI: $10.12746 /$ swrccc2016.0416.212

\section{REFERENCES}

1. Roberts CM, Lowe D, Bucknall CE, Ryland I, Kelly Y, Pearson MG. Clinical audit indicators of outcome following admission to hospital with acute exacerbation of chronic obstructive pulmonary disease. Thorax. 2002; 57(2):137-141. 2. Ford ES, Croft JB, Mannino DM, Wheaton AG, Zhang X, Giles WH. COPD surveillance--United States, 1999-2011. Chest 2013;144:284-305.

3. Halbert RJ, Natoli JL, Gano A, Badamgarav E, Buist AS, Mannino DM. Global burden of COPD: systematic review and metaanalysis. Eur Respir J. 2006;28:523-532.

4. Celli BR, MacNee W, committee members. Standards for the diagnosis and treatment of patients with COPD: a summary of the ATS/ERS position paper. Eur Respir J 2004; 23: 932-946.

5. Groenewegen KH, Schols AMWJ, Wouters EFM. Mortality and mortality- related factors after hospitalization for acute exacerbation of COPD. Chest 2003; 124(2):459-467.

6. Guerrero M, Crisafulli E, Liapikou A, et al. Readmission for Acute Exacerbation within 30 Days of Discharge Is Associated with a Subsequent Progressive Increase in Mortality Risk in COPD Patients: A Long-Term Observational Study. PLoS One 2016;11:e0150737. 7. Hurst JR, Donaldson GC, Quint JK, Goldring JJ, BaghaiRavary R, Wedzicha JA. Temporal clustering of exacerbations in chronic obstructive pulmonary disease. Am J Respir Crit Care Med 2009;179:369-74. 
8. Tsui MS, Lun FC, Cheng LS, et al. Risk factors for hospital readmission for COPD after implementation of the GOLD guidelines. Int J Tuberc Lung Dis 2016;20:396-401. 9. Almagro P, Barreiro B, Ochoa de Echaguen A, et al. Risk factors for hospital readmission in patients with chronic obstructive pulmonary disease. Respiration 2006;73:311-7. 10. Jack BW, Chetty VK, Anthony D, et al. A reengineered hospital discharge program to decrease rehospitalization: a randomized trial. Ann Intern Med 2009; 150(3):178 -187. 11. Koehler BE, Richter KM, Youngblood L, et al.

Reduction of 30-day postdischarge hospital readmission or emergency department (ED) visit rates in high-risk elderly medical patients through delivery of a targeted care bundle. J Hosp Med 2009; 4(4): 211-218

12. Jennings JH, Thavarajah K, Mendez MP, Eichenhorn M, Kvale P, Yessayan L. Predischarge bundle for patients with acute exacerbations of COPD to reduce readmissions and ED visits: a randomized controlled trial. Chest 2015 May; 147(5):1227-34.

13. Gavish R, Levy A, Dekel OK, Karp E, Maimon N. The association between hospital readmission and pulmonologist follow-up visits in patients with COPD. Chest 2015 Aug; 148(2):375-81.

14. Krishnan JA, Gussin HA, Prieto-Centurion V, Sullivan JL, Zaidi F, Thomashow BM. National COPD

Readmissions Summit 2013: Integrating COPD into patient-centered hospital readmissions reduction programs. Chronic Obstr Pulm Dis 2015; 2(1): 70-80.

15. Gimeno-Santos E, Frei A, Steurer-Stey C, et al; PROactive Consortium. Determinants and outcomes of physical activity in patients with COPD: a systematic review. Thorax 2014; 69(8):731-739[published correction appears in Thorax 2014; 69 (9):810]. 